\title{
Prosodic Problems in Children with Autism
}

\author{
Tri Wahyu Retno Ningsih, F.X. Rahyono, Lilie Mundalifah Roosman \\ Universitas Indonesia, Jakarta, Indonesia \\ viayumna@yahoo.com,fxrahyono@gmail.com, lilie.mundalifah@ui.ac.id
}

\begin{abstract}
Prosodic gives a lot of information relevant to understanding of spoken messages. In addition, prosodic in signaling understanding in language interaction. The aim of this study was to point out, the possible recurring patterns in the pitch contours of children in autism. This project was the development of an analysis or synthesis tool in PRAAT that extracts prosodic features from a speech signal and furthermore, creates a syntactic signal consisting of these features only. We give a description of the prosodic analysis, and implementation details and discuss its feature extension capabilities as well. The results of the present study showed that prosodic in its conversational context is useful in order to reveal possible functions of features that would have been overlooked with a more deficit prosodic in autism.
\end{abstract}

Keywords: prosodic, autism, deficit prosodic, PRAAT.

\section{INTRODUCTION}

Prosody is often referred to as the speech pitch and refers to the use of speech for the purpose of language. Prosody components, such as intonation (pitch), stress, and rhythm pattern (rate, phrasing, timing) conjoin to form patterns, such as segmental speech limit, e.g. words, phrases, or sentences. Therefore, the components are included in the suprasegmental prosodic. Suprasegmental patterns affect communication because these patterns contain information of syntax, semantics and pragmatics.

Prosody can be categorized into three categories, namely grammatical, pragmatic, and affective. Grammatical prosody can be used to distinguish whether the same word serves as a noun or a verb. In English, grammatical prosody represents syntactic information in the sentence, for example fluctuating pitch of speaker, depending on the form of the sentence pronounced, whether declarative or interrogative (Shriberg \& Kwiatkowski (1990), Cohen \& Volkmar (1997).

A pitch declination, the fundamental frequency of a speaker begins with a higher frequency pitch in the beginning of the sentence and declines nearing the end of a sentence, even though the pitch declination falls into the realm of psychology and anatomy (Kutik, Cooper, \& Boyce 1983; Ferrand, 2001), it can also provide cognitive and paralinguistic information for the listeners (Kutik, et al. 1983).

In the case of prosody, speakers with autism or Autism Spectrum Disorder (ASD) are often characterized by the emergence of inflection or bad sound changes as well as the pressure of excessive or wrong in giving stresses (Hargrove, 1997). It is recorded as 'strange' speech by doctors and researchers (Fay and Schuler 1980: 31). Some findings regarding prosody in ASD, state that the speaker with ASD has a normal prosody (Fine et al., 1991 \&Thurber \& TagerFlusberg's, 1993). Meanwhile in the Fosnot and

Jun's (1999) study, as well as in Shriberg et al. (2001) study, it showed differences in the results and said that the ASD speakers are not fluent in producing prosody.

This study aims to find prosody disorders in ASD. This study used PRAAT software designed by Paul Boersma and David Weenink (2001) of Phonetic Sciences Department of the University of Amsterdam. PRAAT is software to analyze and reconstruct sound flexibly and it can be used to do many things, ranging from the spectrogram analysis, sounds reconstruction to making diagrams or pictures.

\section{RESEARCH METHODS}

This research is a phonetic experimental. Speech production was obtained from the recording process from the informants using reading stimulus. The results were analyzed by using applications of speech production PRAAT (Boersma \& Weenink, 2001). The components used in the experimental study of speech by utilizing application PRAAT are:

1. Participants: The informant is a speaker with ASD, aged 9years old (Informant 1) and 11 years old (informant 2), respectively.

2. Instrument: Stimulus or technique to read Instruments sentences are four types of sentences, the declarative sentences, echoic interrogative sentences, interrogative sentences with 'what' question, and interrogative sentences with the particle.

Sentence Instruments:

1. He went to school

(Dia pergi ke sekolah) (Subject- VerbComplement)/(Declarative sentences)

2. He went to school?

(Dia pergi ke sekolah?) Subject- Verb-Complement) / (echoic Interrogative sentences Interrogative 1)

3. Did he go to school?

(Apa dia pergi ke sekolah?) (Interrogative sentences with 'what' question words- Interrogative 2)

4. He went to school, didn't he?

(Dia pergi ke sekolah kan?) (Interrogative sentence with the particle.-Interrogative 3)

5. Tools and materials:

Recorder: SONY ICDX;

Hardware:

Processor: Intel Pentium 4, Hard Drive: 50GB, Memory:

512 MB, VGA: 256 MB, Mouse and Keyboard;

Software: PRAAT

6. Instruments: Written text (TNR, font size 12). 
Recording Room: therapy room (a soundproof room) located in a school for Student with Disabilities Inclusion

\section{RESULTS AND DISCUSSION}

Based on the analysis of acoustic data by using PRAAT, the researcher got speech production from two ASD speakers in the same elementary school, but with different ages. ASD 1 was 9.2 year old (in the third grade), and the second informant, ASD was 11, 4 years old in Grade 5. Table 1 describes the acoustic analysis of the value of F0.

\section{I1: informant 1; I2: informant 2}

Based on Table 1, it is gained an overview of the F0 value and the value of the initial pitch and the final pitch of the speech are obtained. The highest F0 value for informant 1 and informant 2 are mentioned in the echoic interrogative sentence. While the lowest value of F0 in informant 1 is the speech that uses instruments with 'what' question, and the lowest production value of $\mathrm{F} 0$ in informant 2 is the value of F0 on the interrogative sentence 2 .

The initial pitch value for informant 1 , the initial pitch value is lower than the final pitch, while the second informant has a declining pitch contour declination although it is gradual. Results of pitch contour analysis, are illustrated generate contours is in Figures 1-4.

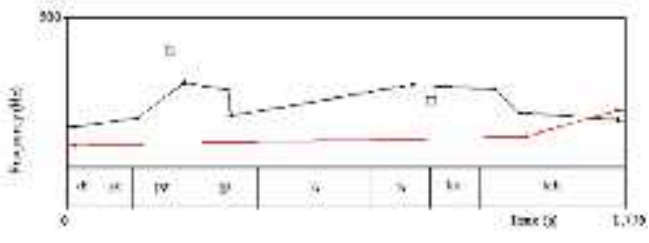

Figure 1. Contour Pitches In Declarative Sentences

Figure 1 describes the different contours based on speech production result between informant 1 (I1) and the informant 2 (I2). Based on the acoustic analysis, it can be explained that informant 1 was not able to make a decrease in the pitch of the final syllable.

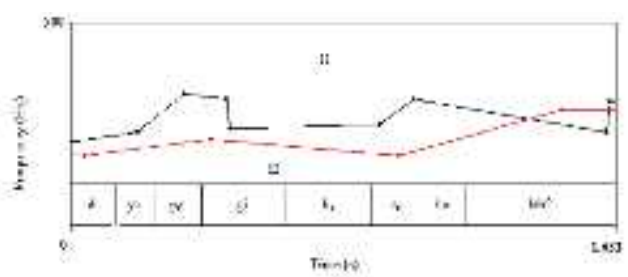

Figure 2. Contour pitch on the mode of echoic interrogative sentences

Figure 2 describes the pitch contour in the mode of interrogative sentences, I1 was able to make an inclination on the final syllable and was distinct from the informant 2 . Informants I2, could not make the contours of inclination on the final syllable.

Table 1. Values f0, 9-years old the initial pitch, and the final pitch(in hz)

\begin{tabular}{|c|c|c|c|c|c|}
\hline Interrogative 3 & Interrogative 2 & Interrogative L & de:larative & & $T 1$ \\
\hline 293.55 & 26730 & $299 . \mathrm{CC}$ & 293.73 & I: & \multirow{2}{*}{ Nean $F$} \\
\hline 185.70 & 27455 & $253 . \mathrm{CS}$ & 239.67 & {$[2$} & \\
\hline 19717 & 7613 & 25546 & 25597 & I & \multirow{2}{*}{ E. min } \\
\hline $16 \div .54$ & $157::-1$ & 214.25 & 21425 & {$[2$} & \\
\hline 328.90 & 45800 & 353.34 & 35.181 & I: & \multirow{2}{*}{ Fo ines } \\
\hline 217.33 & 329,90 & 219.61 & 29593 & {$[2$} & \\
\hline 245 & 144.2 & 257.5 & 256 & I: & \multirow{2}{*}{ inirial pitch } \\
\hline $1 / 1$ & $15 / .2$ & 225.2 & $2 \mathrm{~L}: \mathrm{H}$ & L2 & \\
\hline 298.7 & 358 & 337.8 & 272.1 & I: & \multirow{2}{*}{ tinal patch } \\
\hline 203.3 & 288.6 & 320.8 & 293.8 & {$[2$} & \\
\hline
\end{tabular}




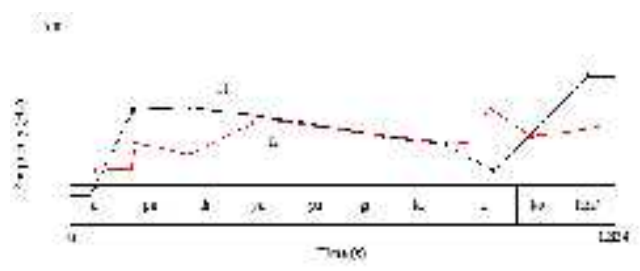

Figure 3. Contour pitch on the mode of interrogative sentences using 'what' question

Figure 3 describes the pitch contour in the mode of interrogative sentences, I1 was able to make an inclination on the final syllable and was distinct from the informant 2 . Informant $\mathrm{I} 2$ was unable to make the inclination contours perfectly.

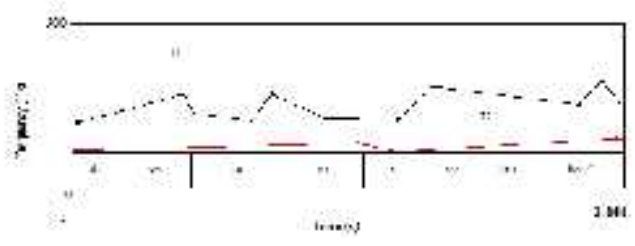

Figure 4. Contour pitch on the mode of interrogative sentences using the 'tag question'

Figure 4 describes the pitch contour in the mode of interrogative sentences using 'tag question', I1 created contour up and down contour, but not consistently. Informants 2 could make the contours rise, although the range of pitch produced was relatively low. The range of pitch, was about $129,2 \mathrm{~Hz}$ between the informant 1 and the informant 2 . F0 value differences in each sentence mode are described in Graphic 1.

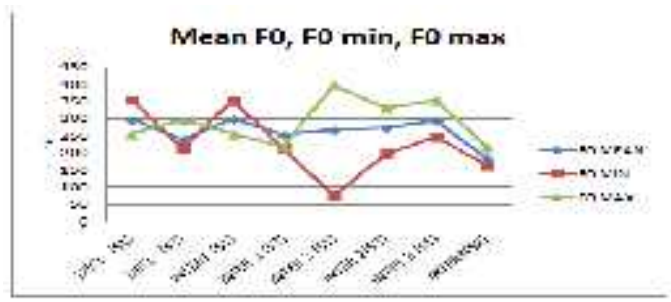

Graphic 1. Graph of f0 value comparison

Analysis on the value of F0 provides information that the highest value, produced by Informant 1 was the echoic interrogative sentences. On the other hand, the lowest F0 was produced by informant 2 on the mode of interrogative sentences 3. The lowest F0 minimal was around $76.13 \mathrm{~Hz}$ produced by informant 1 on the interrogative sentences 2 . F0 maximal was produced by informant 1, with $256.46 \mathrm{~Hz}$ in interrogative sentences 1. Measurement of the duration of the speech has been done by segmenting syllables. Analysis of utterance duration is described in Table 2.

Table 2. The duration of the speech in asd (in second)

\begin{tabular}{|c|c|c|c|c|c|c|c|c|}
\hline gi & $p x$ & ya & di & $\mathrm{pa}$ & a & & Syllable & \\
\hline 0.299 & 0.295 & 0.261 & $0.2 \mathrm{C} 4$ & & & II & \multirow[t]{2}{*}{ Deciarative } & \\
\hline 0.201 & 0.111 & 0.01 & 0.01 & & & I2 & & \\
\hline 032 & 0297 & 0306 & 0266 & & & TI & \multirow[t]{2}{*}{ Intermgative 1} & \\
\hline 0.242 & 0.146 & 0.113 & 0.136 & & & I2 & & 8 \\
\hline 0.191 & 0.202 & 0.23 & 0.206 & 0.237 & C. 258 & Il & \multirow[t]{2}{*}{ Interrogative 2} & \\
\hline 0.112 & 0.174 & 0.213 & 0.149 & 0.213 & C.116 & I2 & & \\
\hline 0.252 & 0.151 & 0.294 & 0.143 & & & II & \multirow[t]{2}{*}{ Intermagative? 3} & \\
\hline 0.213 & 0.119 & 0.213 & 0.116 & & & II & & \\
\hline
\end{tabular}

I1: informant 1; I2: informant 2

Based on the duration table, informant 1 eliminates the preposition 'ke', when reading the instrument 'he went to school' (Dia pergi ke sekolah) on the mode of declarative sentences and interrogative sentences. Informant 1 produced more stable, duration than that of informant 2 . The longest duration is the duration of the constituent objects; that is final syllable on the mode of interrogative sentences in 0.462 second. In the mode of interrogative sentences by using the particle 'kan', which is produced by informant 1 , the longest duration was found on the final syllable. However, informant 2 produced varying durations compare with informant 1 . 
There is a tendency to shorten the duration of constituent objects, when present particle 'kan' is present. Production instability of pitch contour and duration may be indicated as a form of prosody disorders in children with autism.

\section{CONCLUSION}

The same flat contour, low speech, and syllable stress are marker contours produced by speakers of ASD. From the both informants, the declarative sentence cannot create falling pitch in the final syllable. They consistently make a rising pitch in the final syllable though it is not significantly. In echoic interrogative sentence mode, each informant was able to produce the rising final pitch, in the constituent objects. This is similar to the instrument interrogative-2. The informants managed to make a final rising pitch in the constituent objects. For interrogative sentence mode on the instrument using the particles, both informants consistently pitch produced was also low. Informant 1 produced more varied pitched. Based on the techniques used in the experiment, it can be concluded that the informants have not been able to recognize punctuation properly represented through the pitch contour and duration of the speech.

\section{REFERENCES}

Boersma, P \& Weenink, D. (2001). PRAAT, a system for doing phonetics by computer. Glot International, 5 (9/10), 341-345.

Cohen, D,J. \&Volkmar, F.R. (1997). Handbook of autism and pervasive developmental disorders 2 th ed. USA: John Wiley \& Sons. Inc.

Tager-Flusberg, H. Paul \& Lord, CE. (2005). Language and communication in autism. In F Volkmar, R. Paul, A. Klin \& D.J. Cohen (Eds). Handbook od autism and pervasive developmental disorder. Third Edition Volume 1(pp.335364). New York: Wiley.

Thurber, C. \& Tager-Flusberg, H. J. (1993). Pauses in the narratives produces by autistic, mentally retarded, and normal children as an index cognitive demand. Journal of Autism and Developmental Diorder 23 (2), 309-322.

Volkmar, F.R. Klin, Siegel, B., Szatmari, P. Lord, C. Campbell, M. Freeman, B.J. Cicchetti, D.V. Rutter, M. \& Kline, W. (1994). "Field trial for autistic disorder in DSM-IV”. American Journal of Psychiatry. 45, 165-170.
Fay, W., \& Schuler, A.L. (1980). Emerging language in autistic children. London: Edward Arnold.

Ferrand, C. T. (2001). Speech Science: An integrated approach to theory and clinical practice. Needdham Heights: Allyn \& Bacon.

Fine, J. Bartolucci. , Ginsberg and Szatmari. (1991) "The use of intonation to communicate in pervasive developmental disorders". Journal of Child Psychology and Psychiatry, 32, 771-782.

Hargrove, P.M. (1997). Prosodic aspect of language impairment in children. Topics in Language Disorders, $17,76-85$.

Jun, S-H. (1999). Prosodic characteristics in children with stuttering or autism during reading and imitation. UCLA: Dept. of Linguistics.

Kutik, EW. J. Cooper, W.E. \& Boyce, S. (1983). "Declination of fundamental frequency in speaker's production of parenthetical and main clauses". Journal of the Acoustical Society of America, 73, 1731-1738.

Shriberg., L \& Kwiatkowski (1990). "The Prosody voice screening profile (PVSP): 1. Description and psychometric studies". Paper presented at the annual convention of the American Speech Language Hearing Association, St. Louis, MO.

Shriberg, L.D., Paul, R., McSweeny, J.L., Klin, A., Cohen, D.J., \& Volkmar, F.R. (2001). "Speech and Prosody Characteristics of Adolescents and Adults With HighFunctioning Autism and Asperger Syndrome". Journal of Speech, Language, and Hearing Research. Vol. 44, 1097-1115. 